\title{
A REFORMA DO ENSINO MÉDIO EM QUESTÃO: ENTRE FALÁCIAS E DESAFIOS
}

\section{THE HIGH SCHOOL REFORM IN QUESTION: BETWEEN FALLACIES AND CHALLENGES}

\author{
FURTADO, Jose Henrique de Lacerda ${ }^{1}$
}

\section{RESUMO}

A reforma do Ensino Médio (EM), aprovada através da Lei no 13.415/2017, preconiza uma série de mudanças no mínimo, controversas, tendo como palavra de ordem a sugestiva e questionável flexibilização. Sendo assim, o presente artigo tem como objetivo central discutir acerca deste cenário de disputas em que a reforma do ensino médio se apresenta, destacando a importância da educação em uma perspectiva emancipatória para a formação do indivíduo. A partir das discussões apresentadas, fica evidente a perspectiva regressiva adotada na formulação desta nova modalidade de Ensino Médio, que ignora a importância do relevante papel que pode ser desempenhado por ele na transformação social e no desenvolvimento do pensamento crítico e reflexivo dos estudantes. Nesse contexto de retrocessos, faz-se imprescindível e urgente, portanto, que a sociedade como um todo se organize, assumindo o protagonismo na luta pela manutenção dos direitos conquistados e pelo controle dos rumos da educação dos jovens brasileiros, na busca constante por uma sociedade mais justa e menos desigual.

PalaVRas-ChaVe: Educação; Emancipação Humana; Flexibilização; Políticas Educacionais; Reforma do Ensino Médio.

\section{ABSTRACT}

In a national context of deepening political and economic crisis in which several neoliberal measures are being implemented, a new high school organization is proposed not only ignoring the many real problems faced daily by Brazilian schools but also evidencing the mercantilist logic with which education has been conducted. Also noteworthy is the context marked by an intertwined scenario of disputed interests in which it was formulated. In this sense, the high school reform, approved by Law No. 13,415 / 2017, calls for a series of controversial changes with the slogan of suggestive and questionable flexibility. This article aims to discuss the scenario of disputes in which the high school reform is presented, highlighting the importance of education in an emancipatory perspective for the formation of the individual. From the discussions presented, become evident the regressive perspective adopted in the formulation of the new high school model which ignores the importance of the relevant role that it can

\footnotetext{
${ }^{1}$ Instituto Federal do Rio de Janeiro (IFRJ) - Campus Pinheiral RJ / Escola Politécnica de Saúde Joaquim Venâncio (EPSJV-FIOCRUZ). Rio de Janeiro, RJ, Brasil. ORCID: https://orcid.org/0000-0003-2257-3531 e-mail: henrilacerda2009@hotmail.com
} 
DOI: $10.12957 / \mathrm{e}-\mathrm{mosaicos} .2020 .46344$

played in the social transformation and the development of critical and reflective thinking of students. In this context of setbacks it is thus essential and urgent that the society as a whole organizes itself, taking the lead in the struggle for the maintenance of rights conquered and the control of the directions of education of young Brazilians, in the constant search for a fairer and less unequal society.

KeYwordS: Education; Human Emancipation; Flexibility; Educational Policies; High School Reform.

\section{INTRODUÇÃO}

Nos últimos 16 anos, o Ensino Médio (EM) tem ganhado destaque nos debates acerca da educação no Brasil, em virtude do seu processo gradativo de expansão e relativa universalização, que permitiram não só a ampliação do acesso a este nível de ensino às pessoas de novos setores sociais, mas também, uma consequente perda do seu caráter tradicionalmente elitista. Tudo isto, tem tornado esse debate cada vez mais acirrado, levantando diversos questionamentos acerca de quais seriam então seus objetivos, sua identidade e, até mesmo, qual seria sua contribuição social (KRAWCZYC; FERRETI, 2017).

Embora reconheçamos que o EM no Brasil apresenta, de fato, uma série de problemas, como "infraestrutura precária das escolas, desvalorização docente (baixos salários, formas de contratação, vínculos com várias escolas), um formato escolar ultrapassado" (KRAWCZYC; FERRETI, 2017, p.35), faz-se oportuno salientarmos que não são essas as motivações das diversas reformas pelas quais o mesmo tem passado ao longo dos últimos anos, mas sim, a falta de consenso acerca de qual modelo de Ensino Médio se deseja para o país (KRAWCZYC; FERRETI, 2017).

Em um contexto nacional de aprofundamento da crise econômica no país, em que diversas medidas de cunho neoliberal vêm sendo implementadas, uma nova organização do EM é proposta, não só ignorando esses problemas reais enfrentados cotidianamente pelas escolas brasileiras, mas também, propondo uma série de mudanças no mínimo, controversas. Essas mudanças podem representar um verdadeiro "atalho para o passado" (CUNHA, 2017, p. 373), em função da retomada da sua função de contenção de acesso ao Ensino Superior, assim como em reformas anteriores (CUNHA, 2017).

Sendo assim, o objetivo central do presente artigo foi discutir acerca do cenário de disputas em que a reforma do EM se apresenta, destacando a importância da educação em uma perspectiva emancipatória para a formação do indivíduo.

Para tanto, ele foi construído a partir de uma revisão bibliográfica, ancorada nas obras de autores que vêm discutindo a temática abordada ao longo dos últimos anos. O texto foi organizado em duas seções, sendo a primeira destinada às discussões relacionadas ao cenário imbricado de interesses político-ideológicos em que a reforma 
DOI: $10.12957 /$ e-mosaicos.2020.46344

do EM se insere, e a segunda, construída com a finalidade de retomarmos algumas discussões a respeito dos desafios enfrentados para a construção do EM em uma perspectiva emancipatória, objetivando não só a formação do indivíduo, mas também, ressaltando o seu potencial para a transformação da realidade social brasileira.

\section{A REFORMA DO ENSINO MÉdIO: UM CENÁRIO DE DISPUTAS}

Nesta seção inicial, nos propomos a compor uma discussão em torno dos diversos interesses em disputa no processo recente de reforma do EM. Este processo se insere em um cenário imbricado de interesses político-ideológicos, que sempre estiveram presentes ao longo dos anos. Conforme descrito por Cury (2002, p. 17) "o ensino médio, entendido como 'etapa final da educação básica', tornou-se constitucionalmente gratuito e, também, por lei ordinária, 'progressivamente obrigatório'"', sendo sua conclusão considerada pré-requisito para obtenção de diploma de educação profissional de nível técnico. No entanto, embora a legitimação da educação como um direito universal, na Constituição Federal de 1988 (BRASIL, 1988), seja um marco importante alcançado mediante muita luta dos movimentos populares, infelizmente essa luta não se encerra na conquista do marco regulatório. É extremamente necessário incluir nesse debate o que seria, de fato, acesso à educação na perspectiva do direito.

Krawczyc e Ferreti (2017) advogam que nunca houve um compromisso real por parte das elites brasileiras com a democratização da sociedade. Neste sentido, Kuenzer (2011) acrescenta ainda que, no que diz respeito à educação

por força das condições materiais que regem o capitalismo e de políticas públicas "professadas", mas não materializadas, na direção da democratização, tem aumentado a inclusão nas diversas modalidades de educação para os que vivem do trabalho, mas precarizam-se os processos educativos, que resultam em mera oportunidade de certificação, o que apenas favorece a inclusão subordinada, ao longo das cadeias produtivas (KUENZER, 2011, p. 43-44).

A autora chama atenção então, para a existência de um processo de inclusão no sistema educacional e da educação profissional, que em virtude de sua desqualificação, acaba por ser excludente (KUENZER, 2011).

Krawczyc e Ferreti (2017) destacam ainda, os diversos interesses que permeiam a formulação de políticas governamentais, as quais

[...] resultam de embates e negociações que envolvem interesses de classes sociais e frações destas, desencadeando disputas entre forças e projetos antagônicos, que se manifestam, por exemplo, por meio de conflitos entre interesses empresariais, internos e externos ao País, 
DOI: $10.12957 / \mathrm{e}-\mathrm{mosaicos} .2020 .46344$

bem como entre estes e os das classes trabalhadoras no atinente aos rumos a serem propostos à educação (KRAWCZYC; FERRETI, 2017, p. 35).

Faz-se oportuno salientarmos também, o processo histórico brasileiro, atravessado de reformas educacionais ocorridas ao longo dos anos, fruto também desse cenário imbricado de interesses e das frequentes disputas político-ideológicas existentes no país.

Neste sentido, a segunda metade da década de 1990 por exemplo, foi palco de um acirramento significativo de questões cruciais no que diz respeito à visão da educação cada vez mais como uma mercadoria e menos como um direito universal conquistado pela classe trabalhadora.

No governo do então presidente Fernando Henrique Cardoso, além da promulgação da Lei de Diretrizes e Bases da Educação Brasileira (LDB 9394/1996), a qual promoveu a retirada da perspectiva da educação politécnica para a organização da Educação Básica e passou a reconhecer pela primeira vez a possibilidade de lucro para as instituições privadas de ensino no país, logo em seguida ocorreu também, uma regressiva reforma educacional, instituída pela Lei n. 9.393/1996. Esta última, regulamentada pelo Decreto n. 2.208/1997, promoveu a separação da formação profissional do Ensino Médio, bem como a organização curricular baseada em competências (CUNHA, 2007; RAMOS, 2017).

Conforme destaca Ramos (2017, p. 28)

Argumentava-se que essa seria a lógica necessária à adaptação dos trabalhadores à reestruturação produtiva, a qual tornava o trabalho flexível, assim como deveria ser, então, a formação profissional. A Educação Profissional Técnica de Nível Médio voltava a ter a função contenedora de acesso ao ensino superior.

Os argumentos utilizados na construção da reforma de 1997, ainda que a mesma tenha sido revogada pela reforma instituída pelo então presidente Luís Inácio Lula da Silva em 2004, por meio do Decreto n. 5.154/2004, sempre se mantiveram presentes nos anos que se seguiram. Ora mais ora menos, sempre ressurgiram no cenário brasileiro, configurando-se como esteira de base na construção da contrarreforma em curso no cenário atual.

Possuem destaque ainda, a atuação de organismos internacionais, como o Banco Mundial por exemplo, que vem mantendo uma constância na recomendação de medidas austeras que afetam principalmente as classes mais pobres, beneficiando 0 mercado em detrimento das necessidades da população. 
DOI: $10.12957 /$ e-mosaicos.2020.46344

Um exemplo clássico e recente da influência exercida por esses organismos internacionais no país foi a publicação do documento intitulado "Um Ajuste Justo: Análise da eficiência e equidade do gasto público no Brasil". O documento foi elaborado pelo Banco Mundial, sob encomenda do próprio governo brasileiro, ainda em 2015, no segundo mandato da então presidente Dilma Rousseff. Foi publicado oficialmente em novembro de 2017, já no governo em curso do presidente Michel Temer, surgindo em um contexto de avanço da implementação das reformas e políticas de cunho neoliberal, já iniciadas no segundo mandato do governo Dilma e aprofundadas no governo Temer.

Para área da educação, o documento do Banco Mundial (2017) faz uma série de apontamentos que demonstram o seu caráter extremamente economicista. Desconsiderando as características próprias de cada região do país, o organismo utiliza a razão aluno-professor como um dos parâmetros para analisar eficiência das escolas sem efetivamente conhecer a real situação das mesmas.

Além disso, propõe ao mesmo tempo, a precarização das relações e das condições de trabalho, criticando o modelo de contratação dos professores através de concurso público e sugerindo como opção o aumento da exploração da força de trabalho, a terceirização da mão de obra e ainda, a privatização de serviços essenciais, como estratégia para melhorar a eficiência dos serviços prestados.

É neste contexto, que a reforma do EM ora proposta pela Lei n. 13.415 , de 16 de fevereiro de 2017, retoma a concepção da reforma proposta pelo Projeto de Lei 6.840, de 2013, tendo como palavra de ordem a flexibilização (KRAWCZYC; FERRETI, 2017). Conforme destaca Ramos (2017), essa contrarreforma em curso, tem como base as piores medidas de reformas anteriores. Ela recupera concepções herdadas da reforma instituída em 1997 no país, e aprofunda ainda mais os retrocessos propostos pelo Decreto que instituiu a essa reforma da década de 1990.

Krawczyc e Ferreti (2017) alertam ainda que, embora o termo flexibilização seja muito tentador para algumas pessoas, por remeter em seu imaginário à ideia de autonomia, livre escolha, criatividade e inovação, este termo pode representar também "desregulamentação, precarização, instabilidade da proteção contra a concentração da riqueza material e de conhecimento, permitindo a exacerbação dos processos de exclusão e desigualdade social" (KRAWCZYC; FERRETI, 2017, p. 36).

Sendo assim, essa reorganização proposta para o EM no Brasil, torna evidente não só o caráter economicista com que a educação vem sendo tratada ao longo dos anos, mas também, o favorecimento do mercado, na manutenção e fortalecimento do modo de produção capitalista, tendo em vista a acumulação de capital (KRAWCZYC; FERRETI, 2017).

Isso fica ainda mais explícito em virtude da possibilidade que é dada pela nova lei de que os estados privatizem parte do serviço educativo, inclusive permitindo parcerias com instituições que ofereçam educação à distância, sempre que demonstrem "notório reconhecimento" (KRAWCZYC; FERRETI, 2017, p. 39). 
DOI: $10.12957 /$ e-mosaicos.2020.46344

Conforme destaca Peroni (2016, p. 3)

As fronteiras entre o púbico e o privado têm se modificado no contexto atual de crise do capitalismo, em que as estratégias de superação neoliberalismo, globalização, reestruturação produtiva e Terceira Via redefinem o papel do Estado, principalmente para com as políticas sociais. O neoliberalismo e a Terceira via, atual social-democracia, têm o mesmo diagnóstico de que o culpado pela crise atual é o Estado e têm o mercado como parâmetro de qualidade.

Assim, o papel do Estado vai sendo ressignificado, retirando o caráter propositivo e viabilizador imprescindível da legislação federal, flexibilizando para as gestões estaduais a responsabilidade da busca por parcerias, que viabilizassem as condições necessárias para a efetivação dessa nova modalidade de EM. Tudo isso reforça mais uma vez o mercado, em detrimento do papel do Estado no investimento em políticas sociais e na garantia dos direitos constituídos.

Conforme sublinha Peroni (2016), altera-se assim o papel do Estado em relação às políticas sociais, prescrevendo a racionalização de recursos e o esvaziamento do poder das instituições públicas, tendo em vista não só o fato de que estas são suscetíveis às pressões e necessidades da população, mas também, por serem consideradas improdutivas, de acordo com a lógica de mercado.

Nessa perspectiva, fica cada vez mais notório os interesses de quem são defendidos a partir da atuação desses organismos internacionais nos países capitalismo dependentes. Os interesses do mercado em detrimento das necessidades da população. Em momento algum participam ou, sequer são consultados os trabalhadores efetivamente envolvidos com a educação brasileira, muito menos a população.

Além disso, fica evidente a lógica de mercado que é dada à educação, o tempo todo tratada como mercadoria. Bem distante da perspectiva emancipatória defendida por Gadotti (2012) e reiterada por Freire (1987) como educação problematizadora, que permite ao indivíduo além de uma formação integral, a possibilidade de emancipar-se.

Conforme destacam Krawczyc e Ferreti (2017) a trajetória educacional experenciada pelo jovem exerce forte influência sobre as suas possibilidades futuras não só de educação e de trabalho, mas também, de desenvolvimento da capacidade de reflexão, pensamento crítico e autonomia. Segundo estes autores, de acordo com sua trajetória educacional

o/a jovem poderá ou não seguir estudando; terá melhores ou piores condições de se inserir no mercado de trabalho formal (e hoje será ou não considerado em condições de empregabilidade); terá maiores ou 
DOI: $10.12957 /$ e-mosaicos.2020.46344

menores possibilidades de desenvolver sua capacidade de reflexão e autonomia, assim como ideias e opiniões próprias, isto é, se constituir num "ser político", que participa da vida da polis, que tem consciência no mundo no qual vive, que não é manipulado por concepções e interesses alheios (KRAWCZYC; FERRETI, 2017, p. 39).

Nessa perspectiva, a concepção de educação adotada na reforma ora proposta, se distancia da sua finalidade principal de formação integral do sujeito, de possibilitar o desenvolvimento do raciocínio crítico e a capacidade de compreensão da realidade social. Com isso, o EM passa a ser proposto mais uma vez, apenas como etapa de adestramento da classe trabalhadora, para composição de mão de obra reserva para o mercado de trabalho.

Sendo assim, essa proposta de flexibilização não pode ser pensada fora do contexto político de desregulamentação de diversas conquistas sociais, tendo em vista que "sob argumento de uma escola neutra, defende-se a inculcação de valores conservadores, que justificam as desigualdades geradas na sociedade capitalista" (KRAWCZYC; FERRETI, 2017, p. 42), buscando com isso, negar e frear as lutas dos diversos movimentos sociais em prol da inclusão e transformação social.

\section{O ENSINO MÉdIO EM QUESTÃO: ENTRE DESAFIOS E POSSIBILIDADES PARA A EMANCIPAÇÃO DO INDIVÍDUO E A TRANSFORMAÇÃO DA SOCIEDADE}

Todo esse processo de reformas educacionais mencionado traz diversas implicações que influenciam diretamente não só, sobre a vida escolar e o trabalho docente, mas principalmente, sobre "o tipo de formação humana - colonizadora e alienadora ou emancipatória" (FRIGOTTO, 2011, p. 19). Diante disso, faz-se necessário discutirmos acerca dos desafios impostos por essa complexa conjuntura, para a construção do EM numa perspectiva emancipatória, objetivando não só a formação do indivíduo, mas também, ressaltando o seu potencial para a transformação da realidade social brasileira.

Tomando como base o argumento falacioso da flexibilização, quase sempre presente nos diversos momentos reformistas das políticas educacionais brasileiras, aproveitamo-nos para retomar o exposto por Ramos (2017, p. 28) que defende que "nas sociedades de classes, o direito, ao pleno acesso à educação, ficou restrito às elites, sendo que, a cada aproximação da classe trabalhadora à educação, algum limite se impôs". E é para essa perspectiva regressiva que a atual reforma do EM aponta mais uma vez.

Em oposição à proposta do Ensino Médio Integrado, discutida largamente nos anos 1980 e retomada a partir da reforma instituída em 2004, por meio do Decreto $n$. 5.154/2004, a atual reforma do EM, baseando-se em argumentos extremamente duvidosos e, ao mesmo tempo, sedutores, busca restringir mais uma vez o acesso da 
DOI: $10.12957 / \mathrm{e}-\mathrm{mosaicos} .2020 .46344$

classe trabalhadora a uma Educação Básica pública e de qualidade, que possibilite, de fato, a emancipação do indivíduo (RAMOS, 2017).

Acreditamos que aí se encontre, um dos principais desafios para a organização de um Ensino Médio no cenário atual. A luta pela garantia do acesso à educação na perspectiva do direito, conquistado mediante muita luta da classe trabalhadora e, por diversas vezes, negado. Conforme destaca Ramos (2017, p. 41):

A luta pelo Ensino Médio Integrado é a luta pelo direito à uma formação humana e plena, tendo o trabalho como princípio educativo em um currículo centrado nas dimensões fundamentais da vida: o trabalho, a ciência e a cultura. Por essa concepção de formação, o conhecimento não é, somente, um insumo ou um instrumento para o desempenho acadêmico ou profissional. Antes, o conhecimento resulta da apreensão da realidade pelos seres humanos, num processo histórico em que buscamos compreender nossas necessidades e produzir meios para satisfazê-las. Esse é o próprio processo do trabalho o qual gera conhecimentos e novos modos de vida.

Diante do cenário de disputas desenhado na seção anterior, faz-se oportuno retomarmos aqui também, o exposto por Saviani (2007), em suas análises acerca da organização do sistema de ensino com base no princípio educativo do trabalho. Saviani (2007) advoga que o ensino médio deve ser organizado tendo como horizonte não o mero adestramento em técnicas produtivas, mas sim, o de propiciar aos alunos o domínio dos fundamentos das técnicas diversificadas utilizadas na produção.

Neste sentido, tendo em vista que as diversas transformações tecnológicas, aliadas à forma como é organizado o trabalho capitalista atualmente, exigem das escolas um trabalhador com um novo perfil, Gadotti (2012) salienta que residem aí, as razões para o crescente interesse dos empresários na reformulação das políticas de educação.

O autor ressalta ainda que, embora essas reformas sustentem a necessidade de uma formação geral, formando trabalhadores polivalentes para o mercado de trabalho, esse tipo de formação de interesse dos empresários não se preocupa com a qualidade dessa educação, nem muito menos com a emancipação do indivíduo, mas sim, consiste em uma educação bancária, acrítica, em uma perspectiva neoliberal oposta à educação problematizadora (emancipatória) (GADOTTI, 2012).

Para Gadotti (2012) uma "perspectiva emancipatória" da educação e do trabalho deve estar comprometida com a transformação do mundo, proporcionando condições para que o indivíduo pense criticamente a realidade e também, respeitando sua dignidade e autonomia. Nessa perspectiva, a educação emancipadora, concepção oposta à educação bancária, pode ser entendida então, como "problematização da realidade visando à sua transformação" (GADOTTI, 2012, p. 02). 
DOI: $10.12957 /$ e-mosaicos.2020.46344

Segundo Freire e Nogueira (1993) a educação tradicional e bancária, cultivava o entendimento equivocado de educação como mero "depósito de conhecimento dentro da inteligência silenciada do educando" (FREIRE; NOGUEIRA, 1993, p. 60). Em oposição a este modelo, cuja prática pedagógica do educador é orientada por transmissão de conhecimentos, Freire (1987) afirma que a educação popular nasce e se nutre do diálogo entre educadores e educandos, emergindo como modelo do tipo crítico e problematizador.

Conforme destaca Gadotti $(2012$, p. 6)

Numa visão emancipatória, devemos reconhecer nesse processo, a justa análise de Marx: as transformações sociais seguem as transformações do modo de produção e o modo de produção se transforma com a transformação dos meios de produção. Ora, hoje o principal meio de produção é o conhecimento que é a base da pesquisa, da inovação e da produção. E nós trabalhamos justamente com o conhecimento. Finalmente a educação pode fazer alguma diferença na mudança estrutural da sociedade.

Gadotti (2012) aponta então, para o potencial transformador da escola o qual, ainda não foi utilizado em favor das grandes reformas sociais e políticas necessárias à transformação da própria educação, ressaltando a imprescindibilidade da luta pelo direito a essa educação emancipadora, que embora não seja de interesse daqueles que se beneficiam do modo de produção capitalista, interessa muito mais às classes trabalhadoras que, em sua maioria, são excluídas dos benefícios advindos do capitalismo.

Conforme destaca Ramos (2017, p. 42) "a atual contrarreforma do Ensino Médio é mais um componente do movimento austericida liderado pelos que estão no poder e por aqueles que buscam o consenso da sociedade civil por artifícios midiáticos e ideológicos", sendo imprescindível a resistência por parte de toda sociedade, a fim de lutar pela superação dos desafios enfrentados reiteradamente, na busca pela garantia do acesso à uma educação básica que possa desenvolver todo seu potencial de emancipação do indivíduo e de transformação da sociedade.

\section{CONSIDERAÇõES FINAIS}

Considerando as discussões aqui apresentadas, fica evidente que para a formulação desse novo modelo de EM proposto, que está em vias de se tornar realidade no país, foram ignorados não só os problemas reais enfrentados cotidianamente pelas escolas brasileiras, mas também, a importância do relevante papel que pode ser desempenhado pelo mesmo na transformação social e no desenvolvimento do pensamento crítico e reflexivo dos estudantes. 
DOI: $10.12957 /$ e-mosaicos.2020.46344

Em detrimento de uma formação integral, de fato, e de uma educação em uma perspectiva emancipatória dos sujeitos, a reforma resulta não só em uma formação aligeirada e deficitária dos estudantes, visando atender às necessidades do mercado, mas também, no reforço das desigualdades sociais.

Diante disso, faz-se imprescindível e urgente, que a sociedade como um todo se organize, assumindo o protagonismo na luta contra a desregulamentação dos direitos conquistados e o controle social das políticas governamentais, na busca constante por uma sociedade mais justa e menos desigual.

Além disso, considerando o que é proposto pela própria Lei de diretrizes e bases da educação nacional como uma das finalidades da educação básica, a de formar o indivíduo para o exercício da cidadania (BRASIL, 1996), faz-se necessário ressaltar ainda, a importância do empenho dos governantes não só com a questão da ampliação do acesso à educação, mas também na garantia das condições para que essa expansão seja realmente viável e de forma qualificada.

\section{REFERÊNCIAS}

BANCO MUNDIAL. Um ajuste justo: análise da eficiência e equidade do gasto público no Brasil. Washington, D.C.: BIRD/Banco Mundial, 2017.

BRASIL. Constituição da República Federativa do Brasil de 1988. Disponível em: http://www.planalto.gov.br/ccivil 03/Constituicao/Constituicao.htm. Acesso em 10 de jan. de 2019.

. Lei no 9394, de 20 de dezembro de 1996. Estabelece as diretrizes e bases da educação nacional. Disponível em: http://www.planalto.gov.br/ccivil 03/LEIS/L9394.htm. Acesso de 20 de jan. de 2019.

CUNHA, L. A. Ensino médio: atalho para o passado. Educ. Soc., Campinas, v. 38, n. 139, p. 373-384, abr.-jun., 2017.

CUNHA, L. A. O desenvolvimento meandroso da educação brasileira: entre o Estado e o Mercado. Educ. Soc., Campinas, v. 28, n. 100 - Especial, p. 809-829, out., 2007.

CURY, C. R. J. Políticas atuais para o ensino médio e a educação profissional de nível técnico: problemas e perspectivas. In: ZIBAS, D. AGUIAR, M. BUENO, M. (Orgs.) $O$ ensino médio e a reforma da educação básica. Brasília: Plano Editora, 2002. Disponível em: http://www.anpedsul2016.ufpr.br/wpcontent/uploads/2015/11/Confer\%C3\%AAncia-deAbertura-Vera-Peroni.pdf. Acesso em 05 de jan. 2019.

FREIRE, P. Pedagogia do oprimido. 17. ed., Rio de Janeiro: Paz e Terra, 1987.

FREIRE, P.; NOGUEIRA, A. Que fazer: teoria e prática em educação popular. 4. ed. Petrópolis, RJ: Vozes, 1993. 
DOI: $10.12957 / \mathrm{e}-\mathrm{mosaicos} .2020 .46344$

FRIGOTTO, G. Novos fetiches mercantis da pseudoteoria do capital humano no contexto do capitalismo tardio. ANDRADE, J.; PAIVA, L. G. As políticas públicas para a educação no Brasil contemporâneo: limites e contradições. Juarez de Andrade, Lauriana G. de Paiva (orgs.). Juiz de Fora: Ed. UFJF. 2011.

GADOTTI, M. Trabalho e educação numa perspectiva emancipatória. Trabalho apresentado no II Fórum Mundial de Educação Profissional e Tecnológica. Democratização, emancipação e sustentabilidade. Florianópolis, SC, 2012.

KRAWCZYK, N.; FERRETI, C. J. Flexibilizar para quê? Meias verdades da "reforma. Revista Retratos da Escola, Brasília, v. 11, n. 20, p. 33-44, jan./jun. 2017. Disponível em: http://www.esforce.org.br. Acesso em: 05 de out. 2018.

KUENZER, A. Z. EM e EP na produção flexível: a dualidade invertida. Revista Retratos da Escola, Brasília, v. 5, n. 8, pp. 43-55, jan./jun. 2011. Disponível em: <http://esforce.org.br>. Acesso em: 10 de jan. 2019.

PERONI, V. M. V. Implicações da relação público-privada para a democratização da educação. Conferência de abertura da XIANPED/Sul, Curitiba - PR, UFPR, 2016.

RAMOS, M. N. Ensino Médio Integrado: Lutas históricas e resistências em tempos de regressão. In: ARAÚJO, A. C.; SILVA, C. N. N. Ensino médio integrado no Brasil: fundamentos, práticas e desafios / Adilson Cesar Araújo e Cláudio Nei Nascimento da Silva (orgs.) - Brasília: Ed. IFB, 2017. 569 p.

SAVIANI, D. Trabalho e educação: fundamentos ontológicos e históricos. Revista Brasileira de Educação, v. 12, n. 34, jan./abr. 2007. Instituto de Aplicação Fernando Rodrigues da Silveira (CAp-UERJ) está licenciada com uma Licença Creative Commons - Atribuição-NãoComercial 4.0 Internacional.

Os direitos autorais de todos os trabalhos publicados na revista pertencem ao(s) seu(s) autor(es) e coautor(es), com o direito de primeira publicação cedido à e-Mosaicos.

Os artigos publicados são de acesso público, de uso gratuito, com atribuição de autoria obrigatória, para aplicações de finalidade educacional e não-comercial, de acordo com o modelo de licenciamento Creative Commons adotado pela revista. 